Overview of LDRD project 05-ERD-050: "Developing a Reactive Chemistry Capability for the NARAC Operational Model (LODI)"

P. Cameron-Smith, K. Grant, P. Connell

February 11,2008 
This document was prepared as an account of work sponsored by an agency of the United States government. Neither the United States government nor Lawrence Livermore National Security, LLC, nor any of their employees makes any warranty, expressed or implied, or assumes any legal liability or responsibility for the accuracy, completeness, or usefulness of any information, apparatus, product, or process disclosed, or represents that its use would not infringe privately owned rights. Reference herein to any specific commercial product, process, or service by trade name, trademark, manufacturer, or otherwise does not necessarily constitute or imply its endorsement, recommendation, or favoring by the United States government or Lawrence Livermore National Security, LLC. The views and opinions of authors expressed herein do not necessarily state or reflect those of the United States government or Lawrence Livermore National Security, LLC, and shall not be used for advertising or product endorsement purposes.

This work performed under the auspices of the U.S. Department of Energy by Lawrence Livermore National Laboratory under Contract DE-AC52-07NA27344. 


\title{
Overview of LDRD project 05-ERD-050: "Developing a Reactive Chemistry Capability for the NARAC Operational Model (LODI)"
}

\author{
Philip Cameron-Smith (PI), Keith Grant, Peter Connell \\ February 7, 2008
}

\section{Purpose of project}

The primary purpose of this project was to provide LLNL/NARAC the ability to simulate arbitrary networks of chemical reactions within their emergency response atmospheric dispersion model (LODI), so that it can handle the reactions relevant to species such as nerve agents, chlorine, and ozone, plus the in situ creation of aerosols from species such as oleum and $\mathrm{UF}_{6}$. This is a unique emergency-response capability that greatly enhances the LLNL/NARAC ability to respond to terrorist attacks and industrial accidents that involve reactive chemistry. This capability will also facilitate detection and monitoring plans for factories and laboratories, including clandestine facilities. The resulting model also has a dual potential for local and regional air-quality studies.

\section{Summary of Results}

We developed and implemented the capability to simulate arbitrary networks of chemical reactions within the LLNL/NARAC emergency response atmospheric dispersion model (LODI), so that it can handle the reactions relevant to nerve agents, chlorine, ozone, and the in situ creation of aerosols from species such as oleum $\left(\mathrm{SO}_{3}\right)$ and $\mathrm{UF}_{6}$. We also went further than our original plans and developed the capability to calculate the heat generated from chemical reactions and aerosol formation, which can be sufficient to cause a cold and dense plume hugging the ground to rise into the atmosphere, then descend to the ground again as droplets.

In particular, we developed and implemented into the LODI model: (1) the semiLagrangian advection scheme we developed, (2) our aerosol dynamics capability, (3) a Gear general chemistry ODE solver, (4) our chemical mechanisms for chlorine, oleum, ozone, and nerve-agents, and (5) the ability to track the heat generated from chemical reactions and aerosol formation. As an incidental benefit, we improved the multiprocessor scaling and memory usage of LODI in order to expedite the simulations for emergency response. We spent a lot of time interacting with the NARAC development team to educate them on the principles and capabilities we developed. We also worked them on the migration of our improvements into the main LODI code base, and that effort is continuing.

The main report is provided in "Final Report for LDRD project 05-ERD-050: Developing a Reactive Chemistry Capability for the NARAC Operational Model (LODI)" (LLNLTR-401274). A detailed description of the aerosol capability we developed and 
implemented is provided separately in "An Aerosol Condensation Model for Sulfur Trioxide" (LLNL-TR-401137).

\section{Auspices}

This work was performed under the auspices of the U. S. Department of Energy (DOE) by the University of California, Lawrence Livermore National Laboratory (LLNL) under Contract No. W-7405-Eng-48. The project (05-ERD-050) was funded by the Laboratory Directed Research and Development Program at LLNL. 